\title{
Oficinas em sexualidade humana com adolescentes
}

\author{
Alysson Massote Carvalho \\ Universidade Federal de Minas Gerais \\ Cristiano Santos Rodrigues \\ Pontifícia Universidade Católica de Minas Gerais \\ Kelma Soares Medrado \\ Universidade Federal de Minas Gerais
}

\begin{abstract}
Resumo
O presente trabalho tem por objetivo apresentar uma experiência de intervenção em orientação sexual com adolescentes em uma cidade do interior de Minas Gerais. Foram sujeitos da intervenção 50 estudantes da $8^{\underline{a}}$ série do ensino fundamental de uma escola municipal da cidade, divididos em 4 grupos, sendo relatada aqui a experiência vivida em um deles, contando com 13 participantes, com idades variando entre 13 e 15 anos, sendo 8 do sexo masculino e 5 do sexo feminino. Utilizando a metodologia de Oficinas em Dinâmica de Grupo procurou-se, juntamente com os adolescentes, a reflexão e elaboração de sentimentos, comportamentos e conhecimentos compartilhados face à sexualidade, levando em consideração suas angústias e inseguranças relacionadas ao tema, e concentrando-se em dialogar sobre os aspectos afetivos e históricos envolvidos na vivência da sexualidade. A partir da análise dos processos grupais, articulados a uma conscientização éticopolítica dos sujeitos envolvidos, observou-se uma reconstrução/ressignificação dos sentidos atribuídos à sexualidade, ao pertencimento de gênero e ao contexto social mais amplo.
\end{abstract}

Palavras-chave: sexualidade; adolescência; processo grupal; oficinas

\begin{abstract}
Workshop in human sexuality with adolescents. The objective of this study was to determine how the intervention in sexual guidance was experienced by adolescents in a small city in Minas Gerais. The research involved $508^{\text {th }}$ grade students of the municipal elementary school, divided into 4 groups. This article focuses on only one of these groups, with 13 members, 8 male and 5 female, of ages varying from 13 to 15 years old. The methodology used was that of workshops in group dynamics in order for the adolescents to reflect on their feelings, behavior and knowledge, in relation to sexuality. Participants' distress and insecurity in facing the topic were taken into consideration, and emphasis was placed on the emotional aspect and the life history of the subjects involved, in their experiences with sexuality. The analysis of this group process, demonstrated a reconstruction / re-definition of meaning for the ideas related to sexuality, to gender and to the wider social context.
\end{abstract}

Keywords: sexuality; adolescence; group process; workshops

A sexualidade tem se erigido como tema privilegiado a ser abordado com adolescentes pelos profissionais de saúde e educadores que atuam junto a este público. No entanto, educar para a sexualidade não é tarefa das mais simples, na medida em que não se reduz meramente à transmissão de informações de um sujeito que sabe para outro que aprende. Sexualidade é algo constituinte do ser humano, e como tal, se apresenta intrinsecamente relacionada ao âmbito privado, mas é também resultado da cultura e das relações sociais estabelecidas por homens e mulheres no decorrer de suas vidas (Carvalho \& Pinto, 2002; Kahhale, 2001; Rena, 2001).
Dada sua pertinência à esfera pública, a sexualidade também interessa ao Estado, principalmente por se constituir, inúmeras vezes, em um problema de saúde pública. A este respeito observa-se que a iniciação sexual precoce associada ao baixo índice de informação tem feito dos adolescentes um grupo de alta vulnerabilidade a doenças sexualmente transmissíveis (DSTs), AIDS e gravidez não-planejada. Dados da Organização Pan-Americana de Saúde (OPAS) revelam que $40 \%$ dos adolescentes brasileiros iniciaram sua vida sexual até os 15 anos de idade e que aproximadamente $20 \%$ das mulheres pertencentes à população urbana e $28 \%$ das de zona rural tiveram seu primeiro filho antes dos 20 anos, e há 
ainda mais de 550.000 jovens entre 15 e 24 anos portadores de HIV/AIDS na América Latina e Caribe (Abramovay, Castro, Pinheiro, Lima, \& Martinelli, 2002).

Diante de tal quadro, o Estado brasileiro tem se posicionado tomando medidas tais como a inserção da Orientação Sexual entre os temas transversais nos Parâmetros Curriculares Nacionais (PCNs) em todos os ciclos escolares (Ministério da Educação e Cultura, 1998). Através dessa medida, o poder público busca partilhar com a família a responsabilidade pela educação sexual de crianças e adolescentes e, embora compreenda a orientação sexual como tendo caráter sobretudo informativo e a sexualidade como prioritariamente biológica e relacionada às funções hormonais (Altmann, 2001), já se trata de um grande avanço.

Neste contexto, a experiência de trabalho aqui apresentada pretendeu ir além de um caráter puramente informativo, buscando uma metodologia capaz de compreender os sujeitos integralmente em suas dimensões biológica, psíquica e social. Procurou-se, juntamente com os adolescentes, refletir e elaborar sobre sentimentos, comportamentos e conhecimentos compartilhados face à sexualidade humana, através de um trabalho que visa revalorizar o diálogo, o autoconhecimento e uma melhor integração entre sentir, pensar e agir (Afonso, 2000). Através de um processo dialógico, foi possível estabelecer um espaço no qual houvesse uma maior reflexão sobre a vivência da sexualidade na adolescência, com abertura para que elaborações e mudanças de postura ante tal aspecto da vida pudessem ser implementadas.

O trabalho de orientação sexual com adolescentes foi realizado em uma cidade do interior de Minas Gerais, como atividade de ensino-extensão, do Departamento de Psicologia da Universidade Federal de Minas Gerais, no primeiro semestre de 2002. Trata-se de uma atividade focada na perspectiva de promoção de saúde, atuando para tal a partir da interface entre psicologia da saúde e psicologia social comunitária. Havendo uma inserção na comunidade via Programa de Saúde da Família (PSF), procura-se uma maior aproximação entre o trabalho desenvolvido pelo PSF e as demandas da população atendida.

Visando uma articulação entre saúde e educação, o trabalho pautou-se por ações clínico-educativas compartilhadas com os adolescentes objetivando, não apenas transformar suas atitudes e comportamentos, mas também propiciar que estabelecessem relações entre a vivência da sexualidade com sua saúde, com a saúde do próprio corpo e com sua auto-estima (Gonçalves \& Godoi, 2002). Assim, para que o adolescente se torne agente na promoção de sua própria saúde, é necessário que conheça o seu corpo e suas formas de obter prazer, conheça os riscos de determinados comportamentos e possa elaborar para sua vida projetos que visem lidar com a sexualidade de forma ética e responsável.

\section{Adolescência e sexualidade}

A adolescência, compreendida como fase de desenvolvimento humano com características que a distingue das demais, é fenômeno recente e fruto da sociedade ocidental. Se- gundo Afonso (2001), a virada do século XIX para o século XX determina a construção do conceito de adolescência como o conhecemos hoje. Inúmeros fatores sociais, culturais e econômicos foram importantes para que a adolescência se erigisse enquanto fase de transição entre a infância e a idade adulta. Dentre estes, destacam-se os avanços na ciência, que prolongaram a expectativa de vida dos indivíduos, e os processos de sofisticação tecnológica, que passaram a exigir um maior período de formação escolar para a inserção no mercado de trabalho (Aguiar, Bock, \& Ozella, 2001). Dessa forma, houve uma extensão da adolescência, havendo processos mais longos e complexos para sua admissão no mundo adulto.

Segundo a Organização Mundial de Saúde (1988), e com base nesse processo de construção sócio-histórica do conceito de adolescência, atualmente, a adolescência congrega as seguintes características: (1) desenvolvimento maturacional, que compreende o amadurecimento sexual e reprodutivo; (2) desenvolvimento cognitivo e emocional, relacionado às características culturais da população na qual o adolescente se encontra inserido; (3) uma crescente independência econômica em relação ao seu grupo familiar.

Assim como o conceito de adolescência compartilhado pela sociedade atualmente veio modificando-se ao longo dos tempos, o mesmo pode-se dizer em relação à sexualidade. $\mathrm{O}$ século XIX também marca o surgimento do termo sexualidade a partir de um entrelaçamento ao longo dos seguintes campos do conhecimento: pedagogia, medicina e demografia (Altmann, 2001). Desde cedo fica demarcado o campo da sexualidade como o da interface entre práticas individuais e a esfera pública.

A sexualidade humana é plurideterminada, remete-nos, a princípio, a uma dimensão biológica, mas também é produzida no contexto social, cultural e histórico no qual o sujeito encontra-se inserido (Kahhale, 2001).

A discussão e a educação em sexualidade com adolescentes tem sido justificada pelos meios biomédicos a partir de uma naturalização da adolescência, tomando-a como fase de crises e explosão hormonal, que tornam os adolescentes susceptíveis aos riscos de DSTs, AIDS e gravidez não planejada e, por conseguinte, os tornam também um problema de saúde pública. Segundo Paiva (1996), tal estratégia mostrouse ineficaz, principalmente por ter se pautado pelo reforço ao medo da morte, da promiscuidade e não incentivou o sujeito sexual, aquele indivíduo capaz de estabelecer para si a regulação de sua vida sexual, compreendendo os diversos fatores relacionados à prática dos sexo arriscado, que vão além do acesso a informação, mas relacionam-se, sobretudo, ao contexto social, que determina papéis sociais, normas vigentes e estabelece padrões diversificados de socialização entre gêneros, levando a posturas também distintas diante da vivência da sexualidade.

O presente trabalho objetivou oferecer um espaço para discussão da vivência dos adolescentes sobre sua sexualidade, levando em consideração suas angústias e inseguranças a ela relacionadas. Os aspectos biológicos concernentes 
à sexualidade não foram negligenciados, mas concentrou-se, sobretudo, em dialogar sobre os aspectos afetivos, sociais e históricos aí também envolvidos. Sendo assim, o trabalho se deu a partir do processo dialético entre diálogo e elaboração das vivências relacionadas à sexualidade.

\section{Método}

Com o intuito de realizar um trabalho que não se reduzisse simplesmente a passar informações sobre a dimensão biológica da sexualidade, mas buscando trabalhá-la enquanto dimensão integradora do ser humano, optou-se por utilizar a metodologia de Oficinas em dinâmica de grupo, a partir dos pressupostos estabelecidos por Afonso (2000), para quem Oficina é:

um trabalho estruturado com grupos, independentemente do número de encontros, sendo focalizado em torno de uma questão central que o grupo se propõe a elaborar, em um contexto social. A elaboração que se busca na oficina não se restringe a uma reflexão racional, mas envolve os sujeitos de maneira integral, formas de pensar, sentir e agir. (p. 9)

A metodologia de Oficinas se utiliza de teorias e técnicas sobre grupos, sendo uma prática de intervenção psicossocial adaptável a diversos contextos. A Oficina tem suas bases e forma de organização originárias da pesquisa-ação, grupos operativos e pedagogia da autonomia. Afonso (2000) propõe uma revisão das diversas contribuições que serviram de base para um projeto em certa medida inovador no trabalho com grupos. Desta forma, convergem para a construção da metodologia de Oficinas em dinâmica de grupo a teoria de campo de Lewin, a teoria psicodinâmica do grupo, como em Freud, Bion, Foulkes e Pichon-Rivière, a pedagogia de Paulo Freire e análise das instituições de Enriquez.

A Oficina integra aspectos pedagógicos e terapêuticos. No entanto, distingue-se de um processo apenas terapêutico ou pedagógico, na medida em que congrega informação e reflexão relacionados com os significados afetivos e as vivências que o tema a ser discutido suscita.

A realização da Oficina pressupõe passos iniciais: análise da demanda, pré-análise da problemática, do contexto e do grupo, levantamento dos temas-geradores, definição do foco, organização em planejamento flexível (implicando contínua transformação, enquanto fluir o processo grupal). Na condução do grupo são utilizadas técnicas de sensibilização, dinamização, comunicação e reflexão, a fim de propiciar a formação de vínculo grupal e demais vetores do processo grupal, respeitando-se a autonomia e o desenvolvimento dos participantes. À coordenação cabe o papel de facilitadora do processo grupal, através da promoção da comunicação, da análise das implicações do sujeito, da rede de vínculos, transferências, contratransferências e relação do grupo com o contexto.

A Oficina não é um método de manipulação, mas constitui-se em método participativo de análise psicossocial, onde os processos podem ser estimulados, mas jamais induzidos, e os resultados advém do trabalho do grupo enquanto rede de relações (Afonso, 2000).

\section{Sujeitos}

Neste artigo são apresentados os resultados da intervenção realizada com um grupo de 13 adolescentes, estudantes da oitava série do ensino fundamental de uma escola municipal, sendo oito do sexo masculino e cinco do sexo feminino, e idades variando entre 13 e 15 anos.

\section{A demanda}

Enquanto instrumento de intervenção psicossocial, a Oficina deve ocorrer a partir da demanda de um grupo social. No entanto, tal demanda pode ser observada de diversas maneiras, a partir de determinadas situações que envolvam elementos sociais, culturais e subjetivos passíveis de serem trabalhados em um grupo. Neste caso, a demanda pelo trabalho em sexualidade com adolescentes surgiu da própria população do município, que via como preocupantes os índices de gravidez entre as adolescentes e o pouco acesso à informação e aos serviços de saúde que este grupo obtinha.

Por se tratar de uma atividade sustentada pela premissa de uma Psicologia que atue como promotora de saúde, optou-se por desenvolver um trabalho que contemplasse a comunidade escolar da cidade, na qual se encontrava inserida grande parte dos adolescentes, através de uma atuação integrada entre Psicologia, Medicina, Odontologia e das Secretarias Municipais de Saúde e Educação. Buscou-se, com essa intervenção, associar um trabalho educativo e clínico, com vistas a aumentar a participação desse segmento da população em conhecimentos e decisões relativas ao seu cuidado com a saúde.

\section{Procedimentos}

Para implementação da intervenção foi escolhida uma escola municipal que concentrava a maior parte dos estudantes do município e que oferecia ensino fundamental regular em três turnos.

Inicialmente, realizaram-se reuniões com a diretora e em seguida com os professores da escola, nas quais os objetivos do trabalho foram informados. A diretora considerou os alunos mais velhos em melhores condições de aproveitar a oportunidade de trabalho com orientação sexual. Assim, a proposta de trabalho foi divulgada entre os alunos e aqueles que se voluntariaram a participar das oficinas foram divididos aleatoriamente, conforme o turno, em quatro grupos com aproximadamente 12 adolescentes em cada.

Ocorreram oito encontros semanais de 1h15min cada, dentro das dependências da escola e em horário normal de aula. Os alunos que participaram dos grupos eram de um nível socioeconômico baixo e já haviam tido a oportunidade de tratar de algumas questões relacionadas à sexualidade nas aulas de ciências do ano anterior.

Para a realização das Oficinas, procedeu-se, primeiramente, a uma análise prévia da demanda dos sujeitos, que visava levantar dados e aspectos relacionados à questão da sexualidade que se mostrassem relevantes para o trabalho em Oficinas. Essa reflexão inicial em torno do tema buscou organizar um planejamento de trabalho, procurando antever questões que pudessem ser suscitadas pelo grupo, mas também 
adotando uma postura flexível, dado que no encontro com o grupo e no transcorrer da Oficina tal planejamento pode e deve ser modificado, atendendo aos interesses que forem surgindo.

A partir desta análise e delimitação do foco da oficina em sexualidade, foram levantados os seguintes temas-geradores: (1) Sexualidade humana: informações gerais, ansiedades e curiosidades; (2) Sexualidade na adolescência; (3) Papéis e funções sexuais; (4) Mitos, crendices e tabus sexuais; (5) Gravidez na adolescência; (6) Métodos contraceptivos; (7) Doenças Sexualmente Transmissíveis (DSTs) e AIDS; e (8) Afetividade (o namoro, o ficar).

\section{Resultados e Discussão}

Nesta seção é apresentada a experiência vivida no grupo de adolescentes participantes da intervenção. O relato privilegia os principais temas abordados nos encontros, que serviram como unidades de referência para se compreender o processo grupal, bem como as expectativas, representações e prováveis mudanças ocorridas frente à vivência da sexualidade na adolescência.

\section{Delimitação dos temas-geradores, informações gerais e curiosidades sobre sexualidade.}

O primeiro momento desta intervenção, realizado em um encontro, visava a apresentação da coordenação e dos participantes, a explicação sobre o funcionamento do trabalho em oficinas, a seleção dos temas-geradores e a identificação dos conhecimentos que os adolescentes tinham sobre sexo e sexualidade. O planejamento deste e dos demais encontros é apresentado no Apêndice.

Assim, o encontro foi iniciado com a apresentação da proposta de trabalho, buscando salientar as diferenças entre oficinas e as aulas de ciências nas quais o tema sexualidade também era abordado. Neste sentido, observou-se o atravessamento da instituição no desenvolvimento do trabalho, pois os participantes esperavam ter mais uma aula, em que o professor fosse ao quadro e eles aprendessem. A técnica inicial serviu um pouco para quebrar esta idéia, além de ter sido um bom instrumento de descontração e conhecimento dos participantes por parte da coordenação.

Em seguida a técnica da caixa de surpresas foi realizada (ver Apêndice). Houve grande disposição do grupo em desenvolver a atividade, sendo que algumas pessoas chegaram a colocar vários papéis na caixa.

A principal atividade deste encontro consistia em discutir sobre as dimensões da sexualidade. Sexo, para estes adolescentes, foi reconhecido como uma relação de caráter genital, advinda de uma necessidade biológica, heterossexual, mas também devendo contemplar as dimensões do prazer, do amor e a prevenção às DSTs. Já a sexualidade foi compreendida por um aspecto relacional, afetivo, prazeroso e também como uma espécie de entidade controladora do sexo genital.

À coordenação coube o papel de dinamizar as discussões em torno da sexualidade, procurando ressaltar que sexo não se resume à genitalidade e à sexualidade enquanto cons- tituinte de todo ser humano, cujas dimensões seriam as de comunicação, reprodução e prazer.

A seguir passou-se à escolha dos temas-geradores que norteariam o trabalho nos encontros subseqüentes. Aqui, cabe ressaltar que a escolha dos temas-geradores assemelha-se à escolha das palavras-geradoras nos círculos de cultura de Paulo Freire (1980), pois os temas selecionados pelos participantes trazem consigo a dimensão da afetividade e contribuem para o fortalecimento do vínculo grupal, na medida em que já se começam a elaborar as inter-relações da tarefa interna com a tarefa externa (Enriquez, 2001; Pichon-Rivière, 1998). Foram selecionados os seguintes temas: relações entre pais e filhos, gravidez na adolescência, aborto, namoro e sexo na adolescência, liberdade entre jovens, sexo com segurança e DSTs.

O encontro foi encerrado com a técnica dar e receber (ver Apêndice), procurando configurar o espaço da oficina como espaço da troca, do aprendizado mútuo e da rede de relações.

\section{Mitos, crendices e tabus sexuais}

Para abordar esta temática, optou-se por compreender como os adolescentes lidavam com as diferentes manifestações da sexualidade, a partir de suas vivências pessoais e dos discursos e/ou práticas que sustentam acerca desta diversidade.

Assim, realizou-se uma atividade abordando inúmeros tabus e a reação dos participantes diante dos rótulos que destacavam comportamentos afetivo-sexuais passíveis de julgamentos moralistas e preconceituosos (ver Apêndice).

Os participantes explicitaram a dificuldade em conviver com (e aceitar) rótulos como os que dizem respeito à homossexualidade, AIDS e aborto. Refletindo sobre os sentimentos suscitados pela atividade e o tratamento comumente reservado às pessoas que assumem práticas afetivo-sexuais distintas dos padrões socialmente desejáveis, os adolescentes ressaltaram a questão da discriminação e do preconceito ligados a tais práticas e o quanto eles próprios se encontram implicados na reprodução e manutenção destes preconceitos.

Neste sentido, a coordenação interveio para propiciar uma maior reflexão acerca dos papéis assumidos pelos indivíduos na sociedade e da necessidade de se estar atento ao modo como tratamos o diferente, o que está à margem.

A discussão em torno da questão dos estereótipos sociais também revelou uma percepção sobre relações e papéis de gênero ainda muito orientada por valores tradicionais. Embora alguns expressem um discurso privilegiando a igualdade, havia uma idéia bastante arraigada de que homens e mulheres têm necessidades distintas no que diz respeito à vivência da sexualidade, com uma primazia masculina sobre a descoberta do corpo, do prazer e da liberdade sexual.

Porém, através da discussão as adolescentes explicitaram seus pontos de vista, falando da dificuldade de romperem com esses modelos de criação, que destinam à mulher um lugar de subalternidade, sobretudo numa cidade pequena. Neste sentido, o grupo apresentou questões sobre as quais podiam refletir acerca das diferenças no modo como homens 
e mulheres vivem sua sexualidade, se são diferenças naturais ou se, ao contrário, são construídas socialmente.

Houve, a partir dessa discussão, um maior envolvimento do grupo com a tarefa externa, sendo que estabeleceram vínculos de confiança com a coordenação e entre si, de modo a poderem se expor mais espontaneamente, revelando seus medos, seus preconceitos e se abrindo ao diálogo e à opinião dos demais participantes, proporcionando um rico espaço de discussão e reflexão acerca da sexualidade na adolescência.

\section{Sexualidade na adolescência}

Tal temática foi abordada focalizando-se, sobretudo, as dimensões estéticas, corporais e de saúde relacionadas à vivência da sexualidade, procurando-se compreender a percepção que os adolescentes tinham do próprio corpo e os cuidados que lhe dispensavam cotidianamente.

Tomando o corpo como objeto de prazer, primeiramente para si próprio, os participantes foram incentivados, utilizando massas de modelar, a construírem um boneco que os representasse, conforme se percebiam e a refletirem sobre essa percepção (ver Apêndice). A experiência foi vivida intensamente, mas apenas em sua dimensão aparentemente externa, ou seja, os modelos foram feitos e refeitos várias vezes, mas uma discussão mais ampliada sobre as relações entre o corpo e a vivência sexual foi inviabilizada pelo grupo.

Para incentivar uma maior discussão entre os participantes, num segundo momento optou-se por levá-los a refletir sobre os cuidados cotidianos que destinavam ao próprio corpo e se percebiam diferenças nesse cuidar para homens e mulheres.

Os participantes ressaltaram que há maior incentivo ao auto-cuidado feminino, sobretudo quando relacionado à estética corporal, posto que há uma exigência social muito grande sobre a beleza e o corpo feminino. Para o grupo, os homens ainda encontram maior liberdade para cuidarem do próprio corpo, visto que seguem padrões estéticos menos rígidos. Disso resulta, segundo eles, a diferenciação no modo como homens e mulheres se posicionam no decorrer da vida, com estas encontrando maiores dificuldades em lidar com o próprio corpo.

Embora tenha sido possível estabelecer uma pequena discussão, percebeu-se uma regressão por parte do grupo. Tal se deu, em certa medida, pelo próprio caráter da primeira atividade (modelagem), que explorava mesmo uma dimensão infantil mais exacerbada e, por outro lado, em decorrência da dificuldade da qual é revestida a discussão em torno do corpo em servir como fonte e possibilidade de obter e oferecer prazer.

Aqui é importante ressaltar que estabelecer uma clara conexão entre corpo e vivência da sexualidade era um pressuposto da coordenação, não necessariamente condizente com a situação específica destes adolescentes, com trajetórias vividas em uma cidade do interior, ainda muito orientada por valores tradicionais no que diz respeito à sexualidade. Também é importante frisar que o desenvolvimento do ser humano se dá de forma integral, através da interconexão de suas dimensões (física, emocional, cognitiva, moral e social).
No entanto, tal desenvolvimento não ocorre de maneira harmônica e sincronizada entre estas diversas dimensões. Assim, o adolescente necessita, por conta das constantes mudanças físicas, reavaliar cotidianamente seus sentimentos e representações relacionados ao corpo, experimentando, ao mesmo tempo, o luto pelo corpo infantil perdido e a expectativa em torno do novo corpo em formação (Aberastury \& Knobel, 1986).

Dessa forma, a regressão vivida pelo grupo esteve ligada a uma dificuldade da coordenação em adotar uma postura mais aproximada, associada ao próprio caráter da relação conflituosa vivida pelos adolescentes com seus corpos.

\section{Métodos contraceptivos, DSTs e AIDS}

Embora as discussões em torno de DSTs, AIDS e métodos contraceptivos tenham permeado todos os encontros, houve momentos específicos para tratá-los.

A temática foi apresentada de forma lúdica, através de jogos e brincadeiras, de modo a tornar as discussões mais agradáveis, explorando mais profundamente a dimensão afetiva envolvida no processo de prevenção.

Foram apresentados os seguintes métodos contraceptivos aos adolescentes: DIU, diafragma, espermicida, método da temperatura, pílulas anticoncepcionais, pílula do dia seguinte, preservativo masculino, preservativo feminino, injeção de hormônios, tabelinha, laqueadura de trompas e vasectomia. Os participantes os manusearam com muito interesse e fizeram várias perguntas à coordenação sobre o funcionamento dos mesmos. Dos métodos apresentados, apenas o preservativo masculino e a pílula anticoncepcional eram amplamente conhecidos entre eles. Alguns, como a injeção de hormônios, a pílula do dia seguinte, método da temperatura e o espermicida eram completamente desconhecidos, e os demais apenas parcialmente conhecidos. O preservativo feminino foi o mais manuseado, pois nenhum dos participantes tinha visto um, embora soubessem de algumas informações sobre ele.

Também foi proposto ao grupo o jogo Aprendendo a Viver (ver Apêndice), na medida em que se pretendia manter a linguagem lúdica, incluindo a temática das drogas e ampliando a discussão em torno das mais diversas práticas afetivo-sexuais.

Uma vez que as questões apresentadas pelo jogo ofereciam a possibilidade dos adolescentes recorrerem às informações e discussões acontecidas em encontros anteriores, este acabou se tornando um dos elementos avaliadores da oficina.

A discussão sobre a utilização dos métodos contraceptivos centrou-se na necessidade do casal decidir qual o melhor momento de ter filhos, ou mesmo da importância de cada pessoa, independentemente de estar numa relação estável, gerir a própria vida sexual, estabelecendo para si o método que considere mais compatível, mas levando-se em conta a necessidade de auxílio médico na adoção de determinados métodos, além de aliar métodos contraceptivos ao uso de preservativos, que são a melhor maneira de se prevenir de DSTs e AIDS. 


\section{Afetividade}

Propondo-se aos participantes uma atividade que os levasse a refletir e explicitar as características (físicas, pessoais, sociais, etc.) que desejavam em um(a) namorado(a), observou-se uma diferença marcante entre as escolhas masculinas e femininas. Para as mulheres, o namorado ideal tinha, na maior parte das vezes, características relacionadas ao amor, companheirismo, carinho, respeito, compreensão e poucas expectativas direcionadas aos aspectos físicos. Já entre os homens, as características recaiam, invariavelmente, em aspectos físicos como tipo de rosto, corpo, cabelos, etc.

A coordenação buscou estabelecer uma discussão sobre tais diferenças referentes às expectativas masculinas e femininas no que diz respeito à escolha do parceiro ideal, relacionando-as com as posturas adotadas por eles na vida diária diante da expressão da afetividade. Assim, os participantes salientaram que os homens costumam estar mais interessados em relações passageiras e na beleza física das mulheres, ao passo que estas se preocupam mais em estabelecer uma relação duradoura, mesmo que o homem não tenha as características físicas mais desejadas. Outra questão que ficou marcante no encontro foi o desejo masculino de adquirir bens materiais e dinheiro para, assim, conquistar mais mulheres, pois, segundo eles, hoje em dia, as mulheres têm se preocupado cada vez mais com a condição financeira dos parceiros.

\section{Avaliação dos encontros e encerramento do grupo}

O último dia de realização da oficina contou com um momento avaliativo e terminou com um lanche coletivo, como forma de confraternização. Iniciou-se abrindo a caixa de surpresas na qual os participantes haviam colocado suas dúvidas no primeiro encontro. Esta técnica mostrou-se um excelente avaliador do caráter pedagógico da oficina, pois, assim como no jogo Aprendendo a Viver, os participantes sempre se remetiam as discussões realizadas durante os encontros para responderem às duvidas, além de terem uma visão mais crítica com relação às mesmas, observando o quanto haviam amadurecido nesses oito encontros e como aprenderam coisas novas de uma forma divertida e, ao mesmo tempo, sem preconceitos ou restrições às suas opiniões.

Em seguida, apresentou-se o mural feito com as fotos que foram tiradas durante os encontros, e cada participante foi solicitado a olhá-las e se lembrar dos mesmos, buscando ressaltar os aspectos positivos e negativos. As avaliações se centraram muito nos aspectos positivos da oficina, falando de como foram bons os encontros, que havia sido a primeira oportunidade da vida deles para tratarem do tema sexualidade de forma tão prazerosa, em que não precisavam ficar intimidados em tecerem suas opiniões e falar de coisas tão íntimas. Segundo eles, em suas casas os pais eram pouco receptivos a falarem sobre sexo, e na escola tal tema só era abordado nas aulas de biologia, mas com um enfoque bastante diferente, sem tanto espaço para discussões e detendo-se mais em aspectos físicos ou mesmo falando muito de doença, o que causava certo embaraço entre os adolescentes. Após a avaliação dos encontros, cada participante retirou uma das fotos do mural para si e o lanche coletivo foi realizado.

\section{Considerações Finais}

Nas últimas décadas do século XX houve um considerável aumento de pesquisas sobre adolescência e suas conseqüências psicossociais. Inúmeras instituições sociais (família, escola, mídia, igreja, entre outras) disputam espaço e autoridade para falar sobre e pelos adolescentes. De um lado há os que consideram os adolescentes uma geração perdida, descompromissada e alienada, por outro há os que vêem nos adolescentes a imagem de um jovem inconseqüente e frequentemente sujeito a gravidez indesejada, a infecção por doenças sexualmente transmissíveis e ao abuso de álcool e drogas. De um modo geral, a adolescência é compreendida como um processo universal circunscrito a uma "fase" de crises psicológicas e hormonais passageiras.

Neste sentido, a necessidade de se trabalhar com sexualidade junto a esse público é muitas vezes justificada pela intenção de fornecer uma base racional para planejarem suas vidas (Afonso, 2001).

No entanto, como a proposta de trabalho relatada neste artigo salienta, a informação racionalizada por si só não basta, uma vez que a mudança de valores e práticas relativos a vivência da sexualidade não é meramente comportamental, mas é sobretudo efetuada a partir da articulação entre fatores objetivos e subjetivos, criando novas formas de organização da comunicação, além de ser dinamizada pela dimensão afetiva, que pode tanto bloquear quanto facilitar os processos de mudança.

Os adolescentes não são, em absoluto, uma massa amorfa e alienada. Há uma multiplicidade de experiências e trajetórias adolescentes e, muitas vezes, os esforços empreendidos para entender esses sujeitos correm sérios riscos de homogeneizálos e desistoricizar suas vivências e contextos sociais. Dessa forma, qualquer estudo sobre adolescência é um estudo datado, pois fala sempre de um momento, de uma geração e de uma cultura específicos, localizados no tempo e espaço.

Tendo tais questões como mote, os resultados obtidos por essa experiência, sustentada por uma metodologia de trabalho dialógica e participativa, possibilitaram aos adolescentes um profícuo espaço de reflexão e elaboração de vivências e experiências no contexto do grupo, fornecendo as bases para a produção de novos sentidos e conduzindo a mudanças em relação à sexualidade. Assim, na oficina o grupo é apresentado como contexto, no qual se podem reconstruir e criar significados, além de revivenciar situações e relações marcantes. Dentro do grupo tais experiências podem ser elaboradas por meio da troca de informações, da produção de insight, da identificação, das reações em espelho e da rede transferencial (Afonso, 2000).

Neste sentido, se a mudança ocorrida no grupo não pode ser quantificada, ela pode, no entanto, ser qualificada. Trata-se de um processo e evolução que, articulados à uma conscientização ético-política dos sujeitos envolvidos, propiciou uma reconstrução/ressignificação dos sentidos atribuídos a sexualidade, ao pertencimento de gênero e ao contexto social mais amplo. Houve um amadurecimento dos participantes dos grupos, habilitando-os a estabelecerem para si uma 
maior regulação de sua sexualidade, associada a uma maior criticidade e compreensão de seu contexto sócio-histórico.

\section{Referências}

Aberastury, A., \& Knobel, M. (1986). Adolescência normal: um enfoque psicanalítico (S. M. G. Balve, Trad.). Porto Alegre: Artes Médicas.

Abramovay, M., Castro, M. G., Pinheiro, L. C., Lima, F. S., Martinelli, C. C. (2002). Juventude, violência e vulnerabilidade social na América Latina: desafios para políticas públicas. Brasília: UNESCO, BID.

Afonso, L. (2000). Oficinas em dinâmica de grupo: um método de intervenção psicossocial. Belo Horizonte: Edições do Campo Social.

Afonso, L. (2001). A polêmica sobre adolescência e sexualidade. Belo Horizonte: Edições do Campo Social.

Aguiar, W. M. J., Bock, A. M. B., Ozella, S. (2001). A orientação profissional com adolescentes: um exemplo de prática na abordagem sócio-histórica. In A. M. B. Bock, M. G. M. Gonçalves, O. Furtado (Orgs.), Psicologia sóciohistórica: uma perspectiva crítica em psicologia (pp. 163-178). São Paulo: Cortez.

Altman, H. (2001). Orientação sexual nos parâmetros curriculares nacionais. Revista Estudos Feministas, 9(2), 575-585. Retirado em 22/março/2003, da SciELO (Scientific Electronic Library Online), http://www.scielo.br/ref.

Carvalho, A., \& Pinto, M. V. (2002). Ser ou não ser... Quem são os adolescentes? In A. Carvalho, F. Salles, M. Guimarães (Orgs.), Adolescência (pp. 1129). Belo Horizonte: Editora da Universidade Federal de Minas Gerais.
Enriquez, E. (2001). O vínculo grupal. In M. N. M. Machado, E. M. Castro, J. N. G. Araújo, \& S. Roedel (Orgs.), Psicossociologia: análise social e intervenção (pp. 61-74). Belo Horizonte: Autêntica. (original publicado em 1994)

Freire, P. (1980). Educação como prática da liberdade. Rio de Janeiro: Paz e Terra.

Gonçalves, B. D., Godói, C. M. B. (2002). Sexualidade e afetividade: o que é isto? In A. Carvalho, F. Salles, M. Guimarães (Orgs.), Adolescência (pp. 61-82). Belo Horizonte: Editora da Universidade Federal de Minas Gerais.

Kahhale, E. M. P. (2001). Subsídios para reflexão sobre sexualidade na adolescência. In A. M. B. Bock, M. G. M. Gonçalves, O. Furtado (Orgs.), Psicologia sócio-histórica: uma perspectiva crítica em psicologia (pp. 179191). São Paulo: Cortez.

Ministério da Educação e Cultura, Secretaria de Educação Fundamental. (1998). Parâmetros Curriculares Nacionais: terceiro e quarto ciclos: apresentação dos temas transversais. Brasília: Autor.

Organização Mundial da Saúde \& Brasil-Ministério da Saúde. (1988). Programa saúde do adolescente. Bases programáticas. Brasília: Autor.

Paiva, V. (1996). Sexualidades adolescentes: sexualidade, gênero e sujeito sexual. In R. Parker \& R. M. Barbosa (Orgs.), Sexualidades brasileiras (pp. 213-234). Rio de Janeiro: Relume Dumará.

Pichon-Rivière, E. (1998). O processo grupal (M. A. F. Velloso, Trad.). São Paulo: Martins Fontes. (original publicado em 1980)

Portarrieu, M. L. B., \& Tubert-Oklander, J. (1986). Grupos operativos. In L. C. Osório (Org.), Grupoterapia hoje (pp. 135-141). Porto Alegre: Artes Médicas.

Rena, L. C. C. B. (2001). Sexualidade e adolescência: as oficinas como prática pedagógica. Belo Horizonte: Autêntica.

Alysson Massote Carvalho, doutor em Psicologia Experimental pela Universidade de São Paulo, é professor adjunto no Departamento de Psicologia da Universidade Federal de Minas Gerais. Endereço para correspondência: Rua Eng. Vicente Assunção, 77 (Itapoá); CEP: 31710-090; Belo Horizonte, MG. Tel.: (31) 34996264. E-mail: alysson@ufmg.br

Cristiano Santos Rodrigues, mestre em Psicologia Social pela Universidade Federal de Minas Gerais, é professor no Instituto de Psicologia da Pontifícia Universidade Católica de Minas Gerais. E-mail: rodriguesbhz@hotmail.com

Kelma Soares Medrado, psicóloga graduada pela Universidade Federal de Minas Gerais. E-mail: kelmedrado@yahoo.com.br 


\section{Apêndice \\ Planejamento dos encontros}

\begin{tabular}{|c|c|}
\hline Técnica & Descrição \\
\hline \multicolumn{2}{|r|}{$1^{1^{0}}$ Encontro } \\
\hline $\begin{array}{l}\text { Apresentação com } \\
\text { bicho de pelúcia }\end{array}$ & $\begin{array}{l}\text { Em círculo, cada participante diz seu nome e dá um beijo em uma parte do corpo do bicho de pelúcia. } \\
\text { Após todos terem se apresentado, são encorajados a beijarem as pessoas que estão à sua direita na } \\
\text { mesma parte do corpo em que beijaram o bicho de pelúcia. }\end{array}$ \\
\hline Caixa de surpresas & $\begin{array}{l}\text { Coloca-se uma caixa no centro do círculo e pede-se que cada participante coloque dentro uma } \\
\text { dúvida sobre sexualidade. Tais questões serão respondidas e debatidas pelos participantes no } \\
\text { último encontro. }\end{array}$ \\
\hline $\begin{array}{l}\text { Vamos falar de } \\
\text { e sexualidade? }\end{array}$ & $\begin{array}{l}\text { Nesta técnica os participantes devem responder em uma folha à pergunta o que é sexo? E depois, } \\
\text { o que é sexualidade? Posteriormente há debate. }\end{array}$ \\
\hline Dar e receber & $\begin{array}{l}\text { Em círculo, os participantes estendem suas mãos, sendo que a direita estará com a palma virada } \\
\text { para cima e a esquerda para baixo. Assim, com as mãos encaixadas, a mão que estiver com a palma } \\
\text { virada para cima recebe e a palma virada para baixo doa. }\end{array}$ \\
\hline \multicolumn{2}{|r|}{$2^{0}$ Encontro } \\
\hline $\begin{array}{l}\text { Cumprimento } \\
\text { estrangeiro }\end{array}$ & $\begin{array}{l}\text { Os participantes são incentivados a se cumprimentarem de maneiras diferentes, como se fossem de } \\
\text { outro país ou planeta. }\end{array}$ \\
\hline Rótulos & $\begin{array}{l}\text { Cada pessoa recebe um rótulo e passa a ser tratada pelos outros de acordo com o rótulo que } \\
\text { recebeu, tentando adivinhar qual é. }\end{array}$ \\
\hline Jogo das frases & $\begin{array}{l}\text { Aproximadamente sessenta assertivas sobre sexo e sexualidade, sendo que cada pessoa tira uma } \\
\text { por vez e diz se concorda ou não com o que está e escrito e porquê. }\end{array}$ \\
\hline \multicolumn{2}{|r|}{$3^{0}$ Encontro } \\
\hline $\begin{array}{l}\text { Relaxamento } \\
\text { induzido }\end{array}$ & $\begin{array}{l}\text { Coloca-se uma música relaxante ao fundo e solicita-se aos participantes que imaginem uma viagem } \\
\text { ao próprio corpo, focalizando sua respiração, observando quais partes do corpo lhes dão mais } \\
\text { prazer, quais partes menos apreciam, como se vêem, como sentem o próprio corpo. }\end{array}$ \\
\hline Modelagem & $\begin{array}{l}\text { Oferece-se aos participantes massa de modelar e solicita-se que, individualmente, modelem uma } \\
\text { figura que os represente, que seja um "espelho" do que eles pensam que são. }\end{array}$ \\
\hline \multicolumn{2}{|r|}{$4^{0}$ Encontro } \\
\hline Cartaz do cotidiano & $\begin{array}{l}\text { Nesta atividade os participantes são divididos em grupos por sexo e são incentivados a representar } \\
\text { através de figuras e/ou frases as atividades nas quais estão envolvidos no seu dia-a-dia, relacio- } \\
\text { nando as que dão prazer, as que são obrigados a fazer, etc. }\end{array}$ \\
\hline \multicolumn{2}{|r|}{$5^{0}$ Encontro } \\
\hline Ouvi dizer que... & $\begin{array}{l}\text { Uma caixa contendo vários métodos contraceptivos embrulhados é entregue ao grupo, sendo que } \\
\text { cada pessoa deve retirar aleatoriamente um e apresentá-lo aos demais membros do grupo, explican- } \\
\text { do como funciona, quais suas indicações, contra-indicações, facilidade de uso, etc. }\end{array}$ \\
\hline Painel & $\begin{array}{l}\text { Enquanto um participante do grupo apresenta um método contraceptivo, outro deve escrever em } \\
\text { uma folha de papel kraft as informações apresentadas. }\end{array}$ \\
\hline \multicolumn{2}{|r|}{$6^{-}$Encontro } \\
\hline \begin{tabular}{|l|l|l} 
Anúncio \\
classificado
\end{tabular} & $\begin{array}{l}\text { Cada participante recebe uma folha de papel, onde escreve um anúncio classificado no qual pede } \\
\text { uma namorada ou namorado, informando as características da pessoa desejada e o que oferece a } \\
\text { esta pessoa. }\end{array}$ \\
\hline Painel & $\begin{array}{l}\text { Nesta etapa divide-se o grupo em dois, por sexo, e pede-se que transcrevam para um painel, através } \\
\text { de fotos, gravuras e textos o anúncio que fizeram individualmente. }\end{array}$ \\
\hline \multicolumn{2}{|r|}{$7^{0}$ Encontro } \\
\hline $\begin{array}{l}\text { Jogo "aprendendo a vi- } \\
\text { ver", do Instituto Kaplan }\end{array}$ & $\begin{array}{l}\text { Trata-se de um jogo divertido e educativo, no qual, através de brincadeiras os adolescentes apren- } \\
\text { dem sobre prevenção de HIV/AIDS, drogas e sexualidade. }\end{array}$ \\
\hline \multicolumn{2}{|r|}{$8^{0}$ Encontro } \\
\hline Caixa de surpresas & $\begin{array}{l}\text { Neste encontro, a caixa onde os participantes colocaram suas dúvidas no } 1^{0} \text { encontro é aberta e cada } \\
\text { pessoa responde a uma questão com base nas discussões que realizaram durante os demais encontros. }\end{array}$ \\
\hline Mural de fotos & $\begin{array}{l}\text { Trata-se de um mural feito com fotos retiradas nos encontros anteriores, retratando as atividades } \\
\text { desenvolvidas nos mesmos. Este mural atua como avaliador, pois os participantes são solicitados } \\
\text { a se lembrarem dos acontecimentos através das fotos e dizerem o que houve de positivo e negativo } \\
\text { no decorrer dos encontros. Depois, cada participante pode escolher uma foto para si. }\end{array}$ \\
\hline Lanch & ante se encarrega de levar uma comida ou bebida para encerrar o encontro com uma festa. \\
\hline
\end{tabular}

